\title{
Tyrosine kinase inhibitor combination therapy in first-line treatment of non-small-cell lung cancer: systematic review and network meta-analysis
}

This article was published in the following Dove Press journal:

OncoTargets and Therapy

5 May 2017

Number of times this article has been viewed

\author{
Sarah Batson' \\ Stephen A Mitchell' \\ Ricarda Windisch ${ }^{2}$ \\ Elisabetta Damonte ${ }^{2}$ \\ Veronica C Munk ${ }^{2}$ \\ Noemi Reguart ${ }^{3,4}$ \\ 'DRG Abacus, Bicester, Oxfordshire, \\ UK; ${ }^{2}$ F Hoffmann-La Roche Ltd, \\ Basel, Switzerland; ${ }^{3}$ Medical \\ Oncology, Hospital Clinic, \\ ${ }^{4}$ Translational Genomics and Targeted \\ Therapeutics in Solid Tumors, \\ Institut d'Investigacions Biomèdiques \\ August $\mathrm{Pi}$ i Sunyer (IDIBAPS), \\ Barcelona, Spain
}

Introduction: The introduction of epidermal growth factor receptor tyrosine kinase inhibitors (EGFR-TKIs) has improved the outlook for patients with advanced non-small-cell lung cancer (NSCLC) with EGFR+ mutations. However, most patients develop resistance, with the result that median progression-free survival (PFS) is $\sim 12$ months. Combining EGFR-TKIs with other agents, such as bevacizumab, is a promising approach to prolonging remission. This systematic review and network meta-analysis (NMA) were undertaken to assess available evidence regarding the benefits of first-line combination therapy involving EGFR-TKIs in patients with advanced NSCLC.

Methods: Literature searches were performed using relevant search terms. Study-level pseudoindividual patient-level data (IPD) were recreated from digitized Kaplan-Meier curve data, using a published algorithm. Study IPD were analyzed using both the proportional hazards and the acceleration failure time (AFT) survival models, and it was concluded that the AFT model was most appropriate. An NMA was performed based on acceleration factors (AFs) using a Bayesian framework to compare EGFR-TKIs and chemotherapy.

Results: Nine randomized controlled trials were identified that provided data for EGFR-TKI therapy in patients with $E G F R+$ tumors. These included studies of afatinib ( $\mathrm{n}=3)$, erlotinib $(\mathrm{n}=3)$, erlotinib plus bevacizumab $(n=1)$ and gefitinib $(n=2)$. Erlotinib plus bevacizumab produced the greatest increase in PFS compared with chemotherapy, with 1/AF being 0.24 ( $95 \%$ credible interval [CrI] 0.17, 0.34). This combination also produced greater increases in PFS compared with EGFR-TKI monotherapy: 1/AF versus afatinib, 0.51 (95\% $\mathrm{CrI} 0.35,0.73)$; versus erlotinib, 0.53 (95\% CrI 0.39, 0.72) and versus gefitinib, 0.46 (95\% CrI 0.32, 0.66). All three EGFR-TKI monotherapies prolonged PFS compared with chemotherapy; estimates of treatment effect ranged from 1/AF 0.53 (95\% CrI 0.48, 0.60) for gefitinib to $1 / \mathrm{AF} 0.46$ (95\% CrI 0.40, 0.53) for erlotinib. There was no evidence for differences between EGFR-TKI monotherapies, as all 95\% CrIs included the null value.

Conclusion: Although data for erlotinib plus bevacizumab came from a single Phase 2 study, the results of the NMA suggest that adding bevacizumab to erlotinib may be a promising approach to improving the outcomes achieved with EGFR-TKI monotherapy in patients with advanced EGFR+ NSCLC.

Keywords: bevacizumab, epidermal growth factor receptor tyrosine kinase inhibitor, network meta-analysis, non-small-cell lung cancer, non-squamous, progression-free survival

\section{Introduction}

The introduction of tyrosine kinase inhibitors (TKIs) directed against the human epidermal growth factor receptor type 1 (HER1)/epidermal growth factor receptor (EGFR) has improved the outlook for patients with newly diagnosed non-small-cell
Correspondence: Sarah Batson DRG Abacus, 6 Talisman Business Centre, Bicester, Oxfordshire, OX26 6HR, UK

Tel +44 I869 24I28I

Email sbatson@teamdrg.com 
lung cancer (NSCLC) who have tumors that harbor EGFR+ mutations. Approximately $10 \%-30 \%$ of patients with NSCLC have such mutations, ${ }^{1}$ which result in constitutive activation of EGFR, which plays a key role in the regulation of cell survival and proliferation. EGFR-TKIs inhibit the constitutive activation of EGFR and induce remissions in patients with advanced disease. The EGFR-TKIs are classed as reversible (erlotinib, gefitinib) or irreversible (afatinib, dacomitinib). While overall survival (OS) in this subgroup of patients ranges from $~ 19-39$ months, according to clinical trial data, and has shown little improvement with the introduction of EGFR-TKIs, progression-free survival (PFS) has been increased from $\sim 6$ to $9-13$ months. $^{2}$

Current guidelines, such as those of the National Comprehensive Cancer Network ${ }^{3}$ and the European Society for Medical Oncology, ${ }^{4}$ recommend testing for EGFR mutations in all patients with advanced non-squamous NSCLC before initiation of first-line therapy. This recommendation is based on the superiority of the EGFR-TKIs afatinib, erlotinib and gefitinib over chemotherapy for EGFR+ tumors in Phase 3 randomized controlled trials (RCTs). ${ }^{5-16}$ All these trials have consistently demonstrated improvements in response rates (ranging from 60-80\%) and PFS (8-13 months) with these agents compared with chemotherapy. In the pivotal trial for erlotinib, performed in a Caucasian population, median PFS increased from 5.2 months for cisplatin plus docetaxel or gemcitabine to 9.7 months for erlotinib monotherapy (hazard ratio [HR] $0.37,95 \%$ confidence interval $[\mathrm{CI}] 0.25,0.54 ; P<0.0001),{ }^{5}$ and in a Phase 3 trial performed in an Asian population, median PFS increased from 5.5 months for gemcitabine plus cisplatin to 11.0 months for erlotinib monotherapy (HR 0.34, 95\% CI 0.22, 0.51;P<0.0001). ${ }^{8}$

Despite the improvements in response and PFS achieved with EGFR-TKI therapy over standard chemotherapy, most of the pivotal Phase 3 trials for EGFR-TKIs have failed to demonstrate significant benefits in OS. . $^{5,9,10,12,14,16,17}$ This may in part reflect the fact that most patients develop resistance to EGFR-TKI therapy and relapse within $\sim 12$ months after initiating therapy. At TKI progression, patients are currently assessed for the T790M mutation, and, if positive, they are treated with a recently approved third-generation TKI - osimertinib. ${ }^{18}$ Approaches to delay the development of resistance, and hence disease progression, are therefore being sought. Promising results have been reported for erlotinib in combination with bevacizumab, an agent recommended for first-line therapy in combination with chemotherapy irrespective of EGFR mutation status. ${ }^{19}$
Preclinical data suggest that erlotinib resistance is associated with a rise in both tumor cell and host stromal vascular endothelial growth factor (VEGF). ${ }^{20}$ Moreover, the combined blockade of the VEGF receptor and EGFR pathways efficiently abrogates tumor growth in TKI resistance models. ${ }^{20}$ Recently, a Phase 2 study of erlotinib plus bevacizumab has demonstrated prolonged median PFS of 16.0 months compared with 9.7 months for erlotinib monotherapy (HR $0.54,95 \%$ CI $0.36,0.79 ; P=0.0015) .{ }^{19}$

Most of the pivotal studies of EGFR-TKIs have compared reversible (gefitinib, erlotinib) or irreversible (afatinib) EGFR-TKI monotherapy with current standard first-line chemotherapy regimens, namely, platinum-based doublet therapy, including cisplatin or carboplatin plus gemcitabine, taxanes or pemetrexed..$^{5-7,9,10,12,14}$ To date, a single study has reported results for a direct comparison between two EGFRTKIs, namely, afatinib and gefitinib. ${ }^{16}$ Thus, there are only limited clinical data regarding the relative efficacies of the approved EGFR-TKIs. A number of meta-analyses have been performed and have been used to compare efficacy outcomes among the approved EGFR-TKIs. ${ }^{2,21-27}$ These report statistically significant benefits in terms of PFS for EGFR-TKIs compared with standard chemotherapy and no significant differences between the three TKIs, but with a trend in favor of erlotinib. Two studies have also included network meta-analyses (NMAs), and both report no significant difference in PFS between the three EGFR-TKIs as monotherapy. ${ }^{25,26}$

In the light of the publication of additional RCT data, our objective was to provide further evidence regarding the relative efficacies of afatinib, erlotinib and gefitinib, ${ }^{8,16}$ based on a systematic review (SR) and meta-analysis. We also aimed to investigate whether combining an EGFR-TKI with another targeted therapy, such as bevacizumab, prolongs PFS compared with TKI monotherapies. A secondary aim was to compare OS, response rates and safety outcomes associated with EGFR-TKIs.

\section{Methods}

SR

An SR was performed in accordance with PRISMA guidelines ${ }^{28}$ to identify RCTs of EGFR-TKIs as firstline treatment for adults with locally advanced or metastatic (Stage IIIb or IV) non-squamous NSCLC having activating EGFR mutations. Searches of MEDLINE InProcess, MEDLINE, Embase and the Cochrane Library were performed via Ovid on March 8, 2016. Supplementary searches of conference proceedings for the American Society 
of Oncology, the European Society for Medical Oncology, the European Lung Cancer Conference and the International Association for the Study of Lung Cancer World Conference on Lung Cancer were carried out for 2013-2016. Search strings included terms for NSCLC and stage of disease, together with terms for the treatments of interest including the term EGFR-TKI. Search results were screened for studies of afatinib, erlotinib, gefitinib or dacomitinib as first-line therapy, alone or in combination regimens, and reporting at least one outcome measure of interest (ie, PFS, OS, time to progression, response rate, safety or health-related quality of life [HRQoL]; Table S1). Only English-language publications and publications with an abstract in English were included.

Citations of interest were identified by one reviewer and verified by a second independent reviewer, based on title and abstract. Full publications were obtained for all citations of interest and were assessed by one reviewer and verified by a second independent reviewer. Any uncertainties were resolved through discussion between reviewers. Data were then extracted into an Excel spreadsheet by one reviewer and checked by a second reviewer. All included references were assessed for risk of bias using a seven-criteria checklist as approved by the National Institute of Health and Care Excellence. ${ }^{29}$

\section{NMA}

A NMA was performed to compare PFS for the EGFR-TKIs of interest and chemotherapy. Relevant data were analyzed from publications identified in the SR, as described in the "Results" section. Data for chemotherapy were taken from the comparator regimens investigated in the selected studies.

Study-level pseudo-individual patient-level data (IPD) for PFS were created using a published algorithm to re-create the IPD based on digitized Kaplan-Meier (KM) curve data. ${ }^{30}$ The study-level IPD were analyzed using both the commonly used proportional hazards $(\mathrm{PH})$ and the acceleration failure time (AFT) survival models in STATA (version 14.1). ${ }^{31}$ The assumptions of the PH and AFT models were explored (using diagnostic plots based on Schoenfeld residuals and quantilequantile plots), and it was concluded that the AFT model was the most appropriate. The NMA was thus performed based on acceleration factors (AFs), and the robustness of the conclusions was explored by performing the NMA using the reported study-level HRs. The inverse AFs (1/AF) from an AFT model represent the same direction of treatment effect as the HRs from a PH model. We therefore report the inverse of the AF so that it can be compared with the results of the
PH model (reported as HRs). The interpretation of $1 / \mathrm{AF}$ is comparable with that of the $\mathrm{HR}$, with values $<1$ indicating prolonged survival versus the comparator.

A Bayesian framework and Markov Chain Monte Carlo (MCMC) simulation were used for modeling, with the inclusion of vague prior distributions. All NMA models were fitted using WinBUGS software (MRC Biostatistics Unit, Cambridge, UK). ${ }^{32}$ The models were run with three chains for a burn-in of 50,000 iterations, and inferences were based on a further 20,000 iterations. The point estimate of the results represented the median of the posterior distribution with associated $95 \%$ credible intervals (CrIs). Surface under the cumulative ranking (SUCRA) values were also determined within WinBUGS for each comparator in the network. These provide a ranking for each treatment relative to the other treatments; a treatment that is certain to be the best will have a SUCRA value of 1, and a treatment that is certain to be the worst will have a SUCRA value of $0 .{ }^{33}$

Inconsistency was formally assessed using the Bucher method, which synthesizes the evidence in each pair-wise contrast of a loop of evidence and tests if the direct and indirect evidences are in conflict. ${ }^{34}$

The base case employed a fixed-effects (FE) model applied to the study-level AF, and data for the different chemotherapy regimens were pooled. The pooling of chemotherapy regimens as a single treatment node is an approach that has been employed in previous metaanalyse $^{2,21-26}$ and allowed for the formation of a connected evidence network in this study. The FE model was used in the base case, as the network was based on a small number of studies and the FE model provided a better model fit compared with the random-effects (RE) model in terms of deviance information criterion and residual deviance. A number of sensitivity analyses were performed in order to assess the robustness of the analyses to changes in the assumptions made. These included employing an RE model, analyzing data for the individual chemotherapy regimens used in the identified studies (ie, cisplatin plus gemcitabine and cisplatin plus docetaxel) and restricting the data to only studies enrolling Asian populations.

\section{Results Identified publications}

A total of 2,436 unique citations of potential interest were identified in the electronic search, and two relevant abstracts were identified in the congress search (Figure S1). Of these, 63 publications relating to 42 unique RCTs were 
considered to meet the inclusion criteria for the SR. These included five studies of erlotinib, three studies of gefitinib and three studies of afatinib; no relevant studies of dacomitinib were identified.

Studies restricted to patients with $E G F R+$ mutations were considered to be most relevant for the NMA. In total, 11 RCTs (described in 23 publications) only enrolled patients with $E G F R+$ mutations and were considered for inclusion in the NMA..$^{5-17,19,35-42}$ Of these, nine trials ${ }^{5,7-11,13-17,19,35-38,40}$ provided relevant data in the form of a KM curve and a HR for PFS and could be used to construct an evidence network to compare PFS for afatinib, erlotinib, gefitinib, erlotinib plus bevacizumab and standard chemotherapy (Figure 1). The remaining two RCTs did not connect into the evidence network and so were not considered further. An assessment of the risk of bias for the studies included in the NMA is provided in Figure S2; five studies were considered to have a low risk of bias, the risk of bias was unclear for three and one was considered to have a high risk of bias.

Study design and patient baseline characteristics were generally similar across all nine studies..$^{5,7-11,13-17,19,35-38,40}$ All studies were open-label RCTs and involved adult patients with EGFR+ mutations and a diagnosis of Stage IIIB or Stage IV NSCLC (Table 1). EGFR-TKI therapy was given until disease progression, unacceptable toxicity or death, and chemotherapy was given for a specific number of cycles or until disease progression, the development of adverse events (AEs) or withdrawal of consent. Crossover to an alternative treatment following disease progression was permitted in two studies. ${ }^{5,8}$ The median age of trial populations ranged from $56-67$ years, and $25 \%-77 \%$ of patients were female. Studies were either confined to patients with an Eastern Cooperative Oncology Group (ECOG) performance status (PS) of 0 or 1 or $>85 \%$ of patients had an ECOG PS of 0 or 1 . Across all studies, most patients had Stage IV disease. Six of the

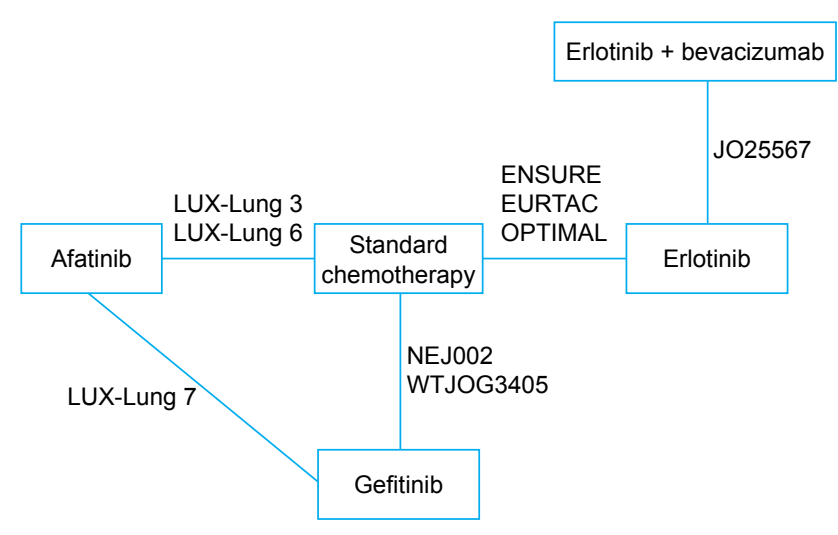

Figure I Evidence network for progression-free survival. studies only included Asian patients, ${ }^{7-10,12,19}$ whereas the LUX-Lung 7 and LUX-Lung 3 trials included the same proportion of Asian and Caucasian (6-15), and the EURTAC was a pure Caucasian population trial. , $16,17^{-17}$

\section{Trial data and NMA results}

Trial-level data for PFS for each study were obtained by modeling pseudo-IPD using the PH and AFT models, and estimates of relative treatment effect are summarized in Table S2.

Results of the base-case NMA are summarized in Table 2 and Figure 2. This analysis found that erlotinib plus bevacizumab showed the greatest increase in PFS compared with standard chemotherapy with $1 / \mathrm{AF}$ being 0.24 (95\% CrI 0.17, 0.34). Furthermore, the SUCRA value of 1.00 indicated that erlotinib plus bevacizumab is certain to have the best outcome of the treatments compared. Values for $1 / \mathrm{AF}$ for erlotinib plus bevacizumab did not include the null value for all four comparisons considered, indicating that this combination regimen prolongs PFS compared with EGFR-TKI monotherapy and compared with standard chemotherapy.

Comparison of values for 1/AF and SUCRA among the TKI monotherapies considered indicated that erlotinib monotherapy showed a greater increase in PFS than afatinib or gefitinib, although inclusion of the null value in the $95 \%$ CrI values for each comparison indicated that there was no evidence for a difference. SUCRA values showed that, among the TKI monotherapies, the greatest PFS benefit was achieved with erlotinib, followed by afatinib and then gefitinib.

All three TKI monotherapies prolonged PFS compared with standard chemotherapy. Values for $1 / \mathrm{AF}$ ranged from 0.53 (95\% CrI 0.48, 0.60) for gefitinib to 0.46 (95\% CrI 0.40, 0.53 ) for erlotinib. The $95 \%$ CIs for all three comparisons did not include the null value, indicating a difference between treatments.

Sensitivity analyses indicated the robustness of these results. The results for the analysis using an RE model are similar to those derived using the FE model but have wider 95\% CrIs, reflecting the uncertainty of the estimate of the between-study standard deviation (Table S3). Using the published HRs rather than 1/AF yielded similar results to those reported for the base case. PFS was prolonged for erlotinib plus bevacizumab for all other therapies considered and for each TKI monotherapy compared with standard chemotherapy; the null value was not included in the $95 \%$ CrIs for any of these comparisons, indicating a difference (Table S4). Results for the individual chemotherapy 
Table I Summary of design and baseline patient characteristics for the studies included in the NMA

\begin{tabular}{|c|c|c|c|c|c|c|c|c|}
\hline \multirow[t]{2}{*}{ RCT } & \multirow{2}{*}{$\begin{array}{l}\text { Treatment } \\
\text { arms }\end{array}$} & \multirow{2}{*}{$\begin{array}{l}\text { Number } \\
\text { randomized }\end{array}$} & \multirow{2}{*}{$\begin{array}{l}\text { Female, } \\
\text { n (\%) }\end{array}$} & \multirow{2}{*}{$\begin{array}{l}\text { Age (years), } \\
\text { median } \\
\text { (range) }\end{array}$} & \multicolumn{3}{|c|}{ ECOG PS, n (\%) } & \multirow{2}{*}{$\begin{array}{l}\text { Duration of } \\
\text { treatment, median } \\
\text { (range) }\end{array}$} \\
\hline & & & & & 0 & $\mathbf{I}$ & 2 & \\
\hline \multirow[t]{2}{*}{$\begin{array}{l}\text { Rosell et al, }{ }^{5} \text { Leon et } \text { al }^{17} \text { and } \\
\text { de Marinis et al, }{ }^{42} \\
\text { (EURTAC) } \\
\text { Phase 3, open-label RCT } \\
\text { Europe (France, Italy, Spain) }\end{array}$} & Erlotinib & 86 & $58(67)$ & $65(24-82)$ & $27(3 \mathrm{I})$ & $47(55)$ & $12(14)$ & $\begin{array}{l}8.2(1-12.0) \text { months } \\
\text { Treatment } \\
\text { scheduled until } \\
\text { disease progression, } \\
\text { development of toxic } \\
\text { effects or withdrawal } \\
\text { of consent }\end{array}$ \\
\hline & $\begin{array}{l}\text { Cisplatin plus } \\
\text { docetaxel or } \\
\text { gemcitabine }\end{array}$ & 87 & $68(78)$ & $65(29-82)$ & $30(34)$ & $45(52)$ & $12(14)$ & $\begin{array}{l}2.8(1.0-2.6) \text { months } \\
\text { Chemotherapy } \\
\text { scheduled for four } \\
\text { 3-week cycles unless } \\
\text { development of toxic } \\
\text { effects or withdrawal } \\
\text { of consent }\end{array}$ \\
\hline $\begin{array}{l}\text { Wu et al }{ }^{6,8} \\
\text { (ENSURE) } \\
\text { Phase 3, open-label RCT }\end{array}$ & Erlotinib & 110 & $(61.8)$ & 57.5 (33-79) & $16(14.7)$ & $87(78.9)$ & $7(6.4)$ & $\begin{array}{l}\text { Treatment scheduled } \\
\text { until progression/ } \\
\text { unacceptable toxicity }\end{array}$ \\
\hline $\begin{array}{l}\text { Asia ( } 30 \text { sites across China, } \\
\text { Malaysia, Philippines) }\end{array}$ & $\begin{array}{l}\text { Cisplatin plus } \\
\text { gemcitabine }\end{array}$ & 107 & $(60.7)$ & $56.0(30-78)$ & $15(14.4)$ & $83(79.8)$ & $6(5.8)$ & $\begin{array}{l}\text { Chemotherapy } \\
\text { scheduled for four } \\
\text { 3-week cycles }\end{array}$ \\
\hline $\begin{array}{l}\text { Mitsudomi et } \mathrm{al}^{7} \text { and Yoshioka } \\
\text { et al }{ }^{35} \\
\text { (WTJOG3405) } \\
\text { Phase 3, open-label RCT } \\
\text { Japan (36 sites) }\end{array}$ & $\begin{array}{l}\text { Gefitinib } \\
\text { Cisplatin plus } \\
\text { docetaxel }\end{array}$ & $\begin{array}{l}88 \\
89\end{array}$ & $\begin{array}{l}59 \\
60\end{array}$ & $\begin{array}{l}64(34-74) \\
64(4 I-75)\end{array}$ & $\begin{array}{l}56(63.4) \\
52(58.4)\end{array}$ & $\begin{array}{l}30(34.0) \\
34(38)\end{array}$ & $\begin{array}{l}N R \\
N R\end{array}$ & $\begin{array}{l}165(22-1,100) \text { days } \\
64(1-106) \text { days }\end{array}$ \\
\hline $\begin{array}{l}\text { Maemondo et al and Inoue et } \mathrm{al}^{36} \\
\text { (NEJ002) } \\
\text { Phase 3, RCT } \\
\text { Japan ( } 43 \text { sites) }\end{array}$ & $\begin{array}{l}\text { Gefitinib } \\
\text { Carboplatin } \\
\text { plus Paclitaxel }\end{array}$ & $\begin{array}{l}114 \\
114\end{array}$ & $\begin{array}{l}72(63.2) \\
73(64.0)\end{array}$ & $\begin{array}{l}(43-75) \\
(35-75)\end{array}$ & $\begin{array}{l}54(47.4) \\
57(50.0)\end{array}$ & $\begin{array}{l}59(51.8) \\
55(48.2)\end{array}$ & $\begin{array}{l}1(0.9) \\
2(1.8)\end{array}$ & $\begin{array}{l}308(|4-|, 2 \mid 9) \text { days } \\
\text { Median } 3-\text { week cycles } \\
\text { was } 4(I-7)\end{array}$ \\
\hline Seto et $\mathrm{al}^{19}$ and Hosomi et al ${ }^{41}$ & Erlotinib & 77 & $26(34)$ & $67.0(60-73)$ & $4 I(53)$ & $36(47)$ & NR & 254 (I8-829) days \\
\hline $\begin{array}{l}\text { (JO25567) } \\
\text { Phase } 2 \text {, open-label RCT } \\
\text { Japan ( } 30 \text { sites) }\end{array}$ & $\begin{array}{l}\text { Erlotinib plus } \\
\text { bevacizumab }\end{array}$ & 77 & $45(60)$ & $67.0(59-75)$ & $43(57)$ & $32(43)$ & NR & $\begin{array}{l}43 I \text { ( } 2 I-837) \text { days } \\
\text { for erlotinib and } \\
325(I-8 \mid 5) \text { for } \\
\text { bevacizumab }\end{array}$ \\
\hline $\begin{array}{l}\text { Zhou et al }{ }^{10,37} \text { and Chen et al }{ }^{\prime \prime} \\
\text { (OPTIMAL) }\end{array}$ & Erlotinib & $\begin{array}{l}83 \\
82\end{array}$ & $\begin{array}{l}48(59) \\
43(60)\end{array}$ & $\begin{array}{l}57(31-74) \\
59(36-78)\end{array}$ & $\begin{array}{l}75(91) \\
69(96)\end{array}$ & & $\begin{array}{l}7(9) \\
3(4)\end{array}$ & $\begin{array}{l}55.5(3.1-93.0) \text { weeks } \\
10.4(1.0-18.9) \text { weeks }\end{array}$ \\
\hline $\begin{array}{l}\text { Phase 3, open-label RCT } \\
\text { China ( } 22 \text { sites) }\end{array}$ & plus carboplatin & & & & & & & \\
\hline $\begin{array}{l}\text { Wu et al, }{ }^{12} \text { Yang et al }{ }^{18} \text { and } \\
\text { Geater et al }{ }^{13} \text { (LUX-Lung 6) }\end{array}$ & Afatinib & 242 & $\begin{array}{l}155 \\
(64.0)\end{array}$ & $58(49-65)$ & $48(19.8)$ & $194(80.2)$ & NR & 389 (173-537) days \\
\hline $\begin{array}{l}\text { Phase } 3 \text {, open-label RCT } \\
\text { China, Thailand and South Korea } \\
\text { (36 sites) }\end{array}$ & $\begin{array}{l}\text { Cisplatin plus } \\
\text { gemcitabine }\end{array}$ & 122 & $83(68.0)$ & $58(49-62)$ & $4 \mathrm{I}(33.6)$ & $81(66.4)$ & NR & $89(60-119)$ days \\
\hline $\begin{array}{l}\text { Sequist et al }{ }^{\mid 4} \text { and Yang et al }{ }^{15,38} \\
\text { (LUX-Lung 3) }\end{array}$ & Afatinib & 230 & $\begin{array}{l}147 \\
(63.9)\end{array}$ & $61.5(28-86)$ & $92(40.0)$ & $138(60.0)$ & NR & II months \\
\hline $\begin{array}{l}\text { Phase 3, open-label RCT } \\
\text { Asia, North America, South } \\
\text { America and Australia ( } 25 \text { sites) }\end{array}$ & $\begin{array}{l}\text { Cisplatin plus } \\
\text { pemetrexed }\end{array}$ & 115 & $77(67.0)$ & $61.0(31-83)$ & $4 I(35.7)$ & $73(63.5)$ & NR & $\begin{array}{l}\text { Chemotherapy } \\
\text { scheduled for up to six } \\
\text { 3-week cycles }\end{array}$ \\
\hline $\begin{array}{l}\text { Park et al }{ }^{16} \\
\text { (LUX-Lung 7) } \\
\text { Phase 2b, open-label RCT } \\
\text { Canada, France, Germany, Ireland, }\end{array}$ & Afatinib & 160 & 57 & $63(30-86)$ & $51(32)$ & $109(68)$ & NA & $\begin{array}{l}\text { Treatment beyond } \\
\text { progression allowed if } \\
\text { deemed beneficial by } \\
\text { investigator }\end{array}$ \\
\hline $\begin{array}{l}\text { Norway, Spain, Sweden, UK, } \\
\text { Australia, China, Korea, Singapore } \\
\text { and Taiwan ( } 64 \text { sites/I } 3 \text { countries) }\end{array}$ & Gefitinib & 159 & 67 & $63(32-89)$ & $48(30)$ & III (70) & NA & \\
\hline
\end{tabular}

Abbreviations: ECOG PS, Eastern Cooperative Oncology Group performance status; NA, not available; NMA, network meta-analysis; NR, not reported; RCT, randomized controlled trial. 
Table 2 Treatment comparisons for PFS: I/AF (95\% Crl), FE model (base case)

\begin{tabular}{|c|c|c|c|c|c|c|}
\hline \multirow[t]{2}{*}{ Treatment A } & \multicolumn{5}{|l|}{ Treatment B } & \multirow[t]{2}{*}{ SUCRA } \\
\hline & Chemotherapy & Afatinib & Erlotinib & Erlotinib + bevacizumab & Gefitinib & \\
\hline Chemotherapy & & $2.07(1.84,2.32)$ & $2.16(1.87,2.49)$ & $4.08(2.89,5.74)$ & $1.87(1.66,2.10)$ & 0.00 \\
\hline Afatinib & $0.48(0.43,0.54)$ & & $\mathrm{I} .04(0.87, \mathrm{I} .25)$ & $1.97(1.37,2.82)$ & $0.90(0.79,1.03)$ & 0.50 \\
\hline Erlotinib & $0.46(0.40,0.53)$ & $0.96(0.80,1.15)$ & & $1.89(1.39,2.57)$ & $0.87(0.72,1.04)$ & 0.75 \\
\hline Erlotinib + bevacizumab & $0.24(0.17,0.34)$ & 0.5 I $(0.35,0.73)$ & $0.53(0.39,0.72)$ & & $0.46(0.32,0.66)$ & 1.00 \\
\hline Gefitinib & $0.53(0.48,0.60)$ & I.II $(0.97,1.27)$ & $1.15(0.96,1.39)$ & $2.18(1.52,3.13)$ & & 0.25 \\
\hline
\end{tabular}

Notes: Results that do not include the null value are shown in bold. Comparisons of row versus column.

Abbreviations: AF, acceleration factor; Crl, credible interval; FE, fixed-effect; PFS, progression-free survival; SUCRA, surface under cumulative ranking curve.

regimens, cisplatin plus gemcitabine and cisplatin plus docetaxel, were similar to those obtained using pooled data for chemotherapy (Table S5). The restriction of the network to trials conducted exclusively in Asian populations also yielded similar results to the base-case analysis.

As part of assessing model validity, NMA estimates for treatment comparisons were compared with direct trial evidence, where it was available (Table S6). The direction of the treatment effects was the same for all direct estimates and the corresponding NMA comparison, with comparable levels of uncertainty. Assessment of consistency for the single loop of evidence within the network yielded a $P$-value of $<0.0001$, which suggests inconsistency within the network. A review of the studies identified race as a potential treatment-modifying covariate. A sensitivity analysis was therefore performed, restricting the analysis to studies only involving Asian populations (ie, excluding the EURTAC and LUX-Lung $3 / 7$ studies). This had little effect on the estimates of treatment effect and no effect on the conclusions of the NMA (Table S7).
Additional outcomes analyzed by NMA include OS, response rates and safety outcomes. The results from these analyses provided little evidence to distinguish between the interventions of interests and are available upon request.

Exploration of PFS in potential subgroups of interest (based on gender, age, smoking and ECOG PS) was not feasible due to the inconsistent reporting of subgroup data across the studies. In addition, it was not possible to perform analyses on the incidence of specific AEs due to inconsistent reporting of these outcomes across the trials. Finally, it was not feasible to conduct an analysis of HRQoL outcomes, which were reported in five trials, each of which employed different instruments to assess HRQoL. . $9-11,13,15^{-15}$

\section{Discussion}

The results of this analysis provide confirmation of the benefit of EGFR-TKIs over standard chemotherapy for first-line therapy in patients with NSCLC having EGFR+ mutations. As in previous analyses, ${ }^{2,21-26}$ no differences in PFS were observed between the three approved EGFR-TKIs,

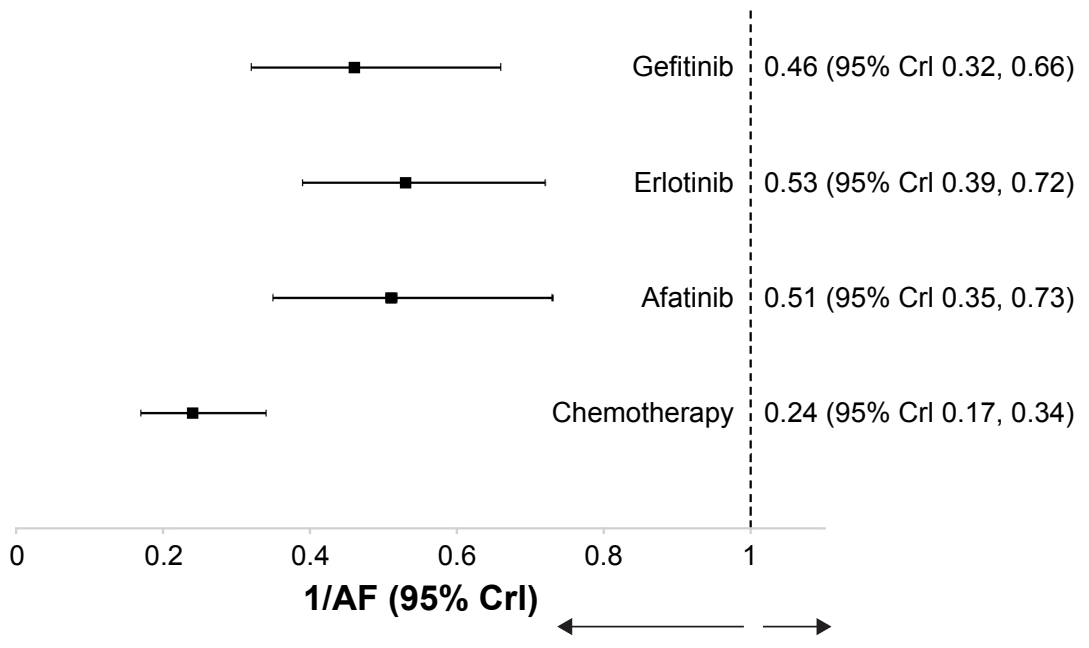

Favors erlotinib + bevacizumab Favors comparator

Figure 2 Forest plot of PFS results for erlotinib + bevacizumab versus comparators (FE model).

Abbreviations: AF, acceleration factor; Crl, credible interval; FE, fixed-effect; PFS, progression-free survival. 
but there was a trend in favor of erlotinib. This was evident both from a comparison of the treatment effect for each of the EGFR-TKIs versus chemotherapy and from treatment effects for comparisons between EGFR-TKIs. Furthermore, the comparison of gefitinib and afatinib suggested a trend in favor of afatinib, consistent with results from the head-tohead trial that reported a benefit for afatinib over gefitinib (HR 0.73, 95\% CrI 0.57, 0.95). ${ }^{16}$

In addition to considering each EGFR-TKI as monotherapy, our analysis also sought to identify RCTs investigating the value of combination regimens involving an EGFR-TKI in newly diagnosed patients with EGFR+ mutations. The SR identified two such studies, one comparing erlotinib plus bevacizumab versus erlotinib monotherapy ${ }^{19}$ and a second comparing gefitinib plus concurrent or sequential chemotherapy. ${ }^{40}$ The erlotinib study was included in the NMA, allowing the efficacy of this regimen to be compared with that of standard chemotherapy, afatinib and gefitinib, as well as with erlotinib monotherapy. ${ }^{19}$ Erlotinib plus bevacizumab was found to provide an improvement in PFS compared with all three EGFR-TKIs as monotherapy, as well as compared with standard chemotherapy. Results of the study assessing gefitinib plus chemotherapy suggested an advantage for combination therapy over gefitinib monotherapy (based on the median PFS of 18 and 15 months reported for the addition of concurrent or sequential chemotherapy, respectively, to gefitinib, compared with 9-11 months reported in studies of gefitinib monotherapy $y^{7,9,35,36,40}$ ). However, this study could not be connected in the NMA. It is therefore currently not possible to assess the efficacy of this combination compared with other EGFR-TKIs.

As demonstrated by our analysis and other published studies, ${ }^{2,21-26}$ there is now a considerable body of evidence concerning the clinical benefits of EGFR-TKIs in patients with $E G F R+$ mutations. While some of the earlier metaanalyses and NMAs have included patients treated in the first- or second-line setting ${ }^{25}$ or have included subgroup data from studies that involved unselected patients (ie, with or without EGFR+ mutations), ${ }^{25,26}$ our study included nine studies conducted specifically in patients with $E G F R+$ mutations receiving therapy in the first-line setting. ${ }^{5,7-11,13-16,19,35-38,40}$ This has the advantage that the patient populations in the nine studies are largely similar, as is also evident from comparison of the baseline patient characteristics for the nine studies. In addition, all nine studies had a similar design, including the planned duration of chemotherapy and EGFR-TKI therapy. Furthermore, the original studies, specifically those in patients with $E G F R+$ mutations, were powered to detect differences between the treatment groups considered in the NMA (which is not necessarily the case when subgroup data are employed). Our analysis therefore provides a robust assessment of the benefits of EGFR-TKI therapy in patients with $E G F R+$ mutations, which is also demonstrated by the consistency of results across all the sensitivity analyses considered.

Most previous analyses have extracted HR values from the individual publications and used these in meta-analyses. We have employed an alternative approach using an AFT model and AF values in our NMA. Given that we found that the $\mathrm{PH}$ assumption does not hold in three of the included studies (NEJ005, JO25567 and LUX-Lung 6) and that the AFT model was deemed an appropriate alternative model for each of the studies, we suggest that use of this alternative approach is more robust.

This analysis is the first to use an NMA to directly compare results between different EGFR-TKIs, between EGFR-TKIs and the EGFR-TKI combination regimen, erlotinib plus bevacizumab, in the relevant patient population. The results of the sensitivity analyses confirm the robustness of the results in terms of the assumptions made regarding the grouping of chemotherapy regimens as a single treatment node and including a mixture of Asian and nonAsian populations. This latter finding is important, as there is published evidence to suggest that, in patients with NSCLC, treated with chemotherapy and targeted agents, Asian ethnicity (compared with Caucasian ethnicity) is associated with increased $\mathrm{OS}$, response rates and toxicity. ${ }^{43}$

The NMA of EGFR-TKIs by Liang et $\mathrm{al}^{25}$ included studies of both first- and second-line therapy. They reported no statistically significant difference between the EGFR-TKI monotherapies and a statistically significant difference between EGFR-TKIs and chemotherapy with respect to PFS and are thus broadly in agreement with the findings from our study. Popat et $\mathrm{al}^{26}$ also reported similar results for an NMA that only involved patients receiving first-line treatment but included some studies comparing two chemotherapy regimens in unselected patient populations (ie, with or without $E G F R+$ mutations) in order to form additional connections in the network.

It is challenging to report robust conclusions on the relative $\mathrm{AE}$ profiles of the comparators investigated: the NMA of the incidence of AEs reported no statistically significant differences between the interventions of interest and an NMA of specific AEs was not feasible due to differences in reporting between studies. A high incidence of hypertension was observed in the $\mathrm{JO} 25567$ trial $^{19}$ in comparison with 
earlier published trials, ${ }^{44,45}$ which the authors suggest may be due to the prolonged duration of treatment and/or the definition of the grading used. Comparisons of AEs reported in two trials conducted exclusively in Asian populations JO25567 $7^{19,41}$ and the LUX-Lung 6 study $^{12}$ - suggest that afatinib is associated with a higher incidence of all-grade diarrhea (88.3\%) compared with erlotinib monotherapy (81\%) and erlotinib plus bevacizumab (78\%).

All trials included in the analysis reported subgroup analyses for PFS by EGFR mutation type (exon 19 deletion and L858R mutation). Two trials reported a statistically significant difference in PFS between the two mutation types in favor of the exon 19 deletion mutation. ${ }^{12,14}$ However, it is noted that these analyses were not powered to detect differences either in PFS between the subgroups or in OS. The majority of trials reported no statistically significant difference in the relative treatment effect for PFS between the EGFR mutation types. This suggests that results from this analysis have validity for both EGFR mutation subgroups.

There are a number of limitations regarding our study. First, study-level pseudo-IPD were created based on digitized KM curve data rather than being based directly on clinical trial data. This is a well-established methodology and has been used before in published NMAs. ${ }^{30,46}$ Furthermore, the HRs estimated based on our analyses of the pseudo-IPD were consistent with those published in the individual trial publications. Second, there are well-recognized limitations associated with the use of NMA rather than direct headto-head studies when comparing treatments. This includes assuming that the patient populations involved in different studies are largely similar and that differences in study design do not substantially influence the observed results. Third, the data for erlotinib plus bevacizumab came from a single Phase 2 study that was conducted in a Japanese population, ${ }^{47}$ which may provide better survival responses compared with a trial conducted in a Caucasian population. ${ }^{43}$ The trial was accepted by the EMA as evidence of the benefits of erlotinib plus bevacizumab, and an approval granted for this indication. ${ }^{47}$ There are several ongoing trials that will report further data on the use of erlotinib plus bevacizumab in this indication, in particular the Phase 3 NEJ026 RCT comparing combination treatment with erlotinib monotherapy in $>200$ patients. $^{48}$

\section{Conclusion}

The results of our analysis provide valuable additional information on the benefits of EGFR-TKI therapy in patients with $E G F R+$ mutations and suggest that combination regimens such as erlotinib plus bevacizumab are a promising approach to improving the outcomes achieved with EGFR-TKI monotherapy. Further studies of combination regimens involving EGFR-TKI and antiangiogenic agents are warranted in this selected population of patients with oncogenic-driven tumors.

\section{Acknowledgment}

This analysis was supported by F Hoffmann-La Roche Ltd.

\section{Disclosure}

SB and SAM are employees of DRG Abacus. RW, ED, and VCM are employees of F. Hoffmann-La Roche Ltd. The authors report no conflicts of interest in this work.

\section{References}

1. Paz-Ares L, Soulieres D, Melezinek I, et al. Clinical outcomes in nonsmall-cell lung cancer patients with EGFR mutations: pooled analysis. J Cell Mol Med. 2010;14(1-2):51-69.

2. Ellis PM, Coakley N, Feld R, Kuruvilla S, Ung YC. Use of the epidermal growth factor receptor inhibitors gefitinib, erlotinib, afatinib, dacomitinib, and icotinib in the treatment of non-small-cell lung cancer: a systematic review. Curr Oncol. 2015;22(3):e183-e215.

3. National Comprehensive Cancer Network (NCCN). NCCN Clincal Practice Guidelines in Oncology (NCCN Guidelines $\left.{ }^{\circledR}\right)$ : Non-Small Cell Lung Cancer. Version 3.2015. 2015. Available from: http://www. nccn.org/professionals/physician_gls/f_guidelines.asp. Accessed February 1, 2017.

4. Novello S, Barlesi F, Califano R, et al. Metastatic non-small-cell lung cancer: ESMO Clinical Practice Guidelines for diagnosis, treatment and follow-up. Ann Oncol. 2016;27(suppl 5):v1-v27.

5. Rosell R, Carcereny E, Gervais R, et al. Erlotinib versus standard chemotherapy as first-line treatment for European patients with advanced EGFR mutation-positive non-small-cell lung cancer (EURTAC): a multicentre, open-label, randomised phase 3 trial. Lancet Oncol. 2012;13(3):239-246.

6. Wu Y, Zhou C, Wu G, et al. Quality of life (QOL) analysis from ensure, a phase 3, open-label study of first-line erlotinib versus gemcitabine/ cisplatin (GP) in Asian patients with epidermal growth factor receptor (EGFR) mutation-positive (MUT+) non-small-cell lung cancer (NSCLC). J Thorac Oncol. 2014;9(4 suppl 1):S37.

7. Mitsudomi T, Morita S, Yatabe Y, et al. Gefitinib versus cisplatin plus docetaxel in patients with non-small-cell lung cancer harbouring mutations of the epidermal growth factor receptor (WJTOG3405): an open label, randomised phase 3 trial. Lancet Oncol. 2010;11(2):121-128.

8. Wu YL, Zhou C, Liam CK, et al. First-line erlotinib versus gemcitabine/ cisplatin in patients with advanced EGFR mutation-positive non-smallcell lung cancer: analyses from the phase III, randomized, open-label, ENSURE study+. Ann Oncol. 2015;26(9):1883-1889.

9. Maemondo M, Inoue A, Kobayashi K, et al. Gefitinib or chemotherapy for non-small-cell lung cancer with mutated EGFR. $N$ Engl J Med. 2010;362(25):2380-2388.

10. Zhou C, Wu YL, Chen G, et al. Erlotinib versus chemotherapy as first-line treatment for patients with advanced EGFR mutation-positive non-smallcell lung cancer (OPTIMAL, CTONG-0802): a multicentre, open-label, randomised, phase 3 study. Lancet Oncol. 2011;12(8):735-742.

11. Chen G, Feng J, Zhou C, et al. Quality of life (QoL) analyses from OPTIMAL (CTONG-0802), a phase III, randomised, open-label study of first-line erlotinib versus chemotherapy in patients with advanced EGFR mutation-positive non-small-cell lung cancer (NSCLC). Ann Oncol. 2013;24(6):1615-1622. 
12. Wu YL, Zhou C, Hu CP, et al. Afatinib versus cisplatin plus gemcitabine for first-line treatment of Asian patients with advanced non-small-cell lung cancer harbouring EGFR mutations (LUX-Lung 6): an open-label, randomised phase 3 trial. Lancet Oncol. 2014;15(2):213-222.

13. Geater SL, Xu CR, Zhou C, et al. Symptom and quality of life improvement in LUX-lung 6: an open-label Phase III study of afatinib versus cisplatin/gemcitabine in Asian patients with EGFR mutationpositive advanced non-small-cell lung cancer. J Thorac Oncol. 2015; 10(6):883-889.

14. Sequist LV, Yang JCH, Yamamoto N, et al. Phase III study of afatinib or cisplatin plus pemetrexed in patients with metastatic lung adenocarcinoma with EGFR mutations. J Clin Oncol. 2013;31(27):3327-3334.

15. Yang JCH, Hirsh V, Schuler M, et al. Symptom control and quality of life in lux-lung 3: a phase III study of afatinib or cisplatin/pemetrexed in patients with advanced lung adenocarcinoma with EGFR mutations. J Clin Oncol. 2013;31(27):3342-3350.

16. Park K, Tan EH, O’Byrne K, et al. Afatinib versus gefitinib as first-line treatment of patients with EGFR mutation-positive non-small-cell lung cancer (LUX-Lung 7): a phase 2B, open-label, randomised controlled trial. Lancet Oncol. 2016;17(5):577-589.

17. Leon LF, Golsorkhi A, Liu S, Drozdowsky A, Rosell R. Overall survival analyses of first-line erlotinib versus chemotherapy in the EURTAC study population controlling for the use of post-study therapy. Ann Oncol. 2014;25(suppl 4):iv447-iv448.

18. Janne PA, Yang JC, Kim DW, et al. AZD9291 in EGFR inhibitor-resistant non-small-cell lung cancer. N Engl J Med. 2015;372(18):1689-1699.

19. Seto T, Kato T, Nishio M, et al. Erlotinib alone or with bevacizumab as first-line therapy in patients with advanced non-squamous non-smallcell lung cancer harbouring EGFR mutations (JO25567): an open-label, randomised, multicentre, phase 2 study. Lancet Oncol. 2014;15(11): 1236-1244.

20. Naumov GN, Nilsson MB, Cascone T, et al. Combined vascular endothelial growth factor receptor and epidermal growth factor receptor (EGFR) blockade inhibits tumor growth in xenograft models of EGFR inhibitor resistance. Clin Cancer Res. 2009;15(10):3484-3494.

21. Burotto M, Manasanch EE, Wilkerson J, Fojo T. Gefitinib and erlotinib in metastatic non-small cell lung cancer: a meta-analysis of toxicity and efficacy of randomized clinical trials. Oncologist. 2015;20(4): 400-410.

22. Haaland B, Tan PS, de Castro G Jr, Lopes G. Meta-analysis of first-line therapies in advanced non-small-cell lung cancer harboring EGFRactivating mutations. J Thorac Oncol. 2014;9(6):805-811.

23. Haspinger ER, Agustoni F, Torri V, et al. Is there evidence for different effects among EGFR-TKIs? Systematic review and meta-analysis of EGFR tyrosine kinase inhibitors (TKIs) versus chemotherapy as firstline treatment for patients harboring EGFR mutations. Crit Rev Oncol Hematol. 2015;94(2):213-227.

24. Lee CK, Brown C, Gralla RJ, et al. Impact of EGFR inhibitor in non-small cell lung cancer on progression-free and overall survival: a meta-analysis. J Natl Cancer Inst. 2013;105(9):595-605.

25. Liang W, Wu X, Fang W, et al. Network meta-analysis of erlotinib, gefitinib, afatinib and icotinib in patients with advanced non-small-cell lung cancer harboring EGFR mutations. PLoS One. 2014;9(2):e85245.

26. Popat S, Mok T, Yang JC, et al. Afatinib in the treatment of EGFR mutation-positive NSCLC - a network meta-analysis. Lung Cancer. 2014;85(2):230-238.

27. Kuan FC, Kuo LT, Chen MC, et al. Overall survival benefits of first-line EGFR tyrosine kinase inhibitors in EGFR-mutated non-small-cell lung cancers: a systematic review and meta-analysis. Br J Cancer. 2015; 113(10):1519-1528.

28. Moher D, Liberati A, Tetzlaff J, Altman DG, Group P. Preferred reporting items for systematic reviews and meta-analyses: the PRISMA statement. BMJ. 2009;339:b2535.

29. National Institute for Health and Care Excellence (NICE). Single technology appraisal: User guide for company evidence submission template; 2015. Available at: https://www.nice.org.uk/process/pmg24/ chapter/instructions-for-companies. Accessed February 1, 2017.
30. Guyot P, Ades AE, Ouwens MJ, Welton NJ. Enhanced secondary analysis of survival data: reconstructing the data from published KaplanMeier survival curves. BMC Med Res Methodol. 2012;12:9.

31. StataCorp. Stata Statistical Software: Release 14. College Station, TX: StataCorp LP; 2015.

32. Lunn D, Jackson C, Best N, Thomas A, Spiegelhalter D. The BUGS Book A Practical Introduction to Bayesian Analysis. Boca Raton, FL: CRC Press; 2013.

33. Salanti G, Ades AE, Ioannidis JP. Graphical methods and numerical summaries for presenting results from multiple-treatment meta-analysis: an overview and tutorial. J Clin Epidemiol. 2011;64(2):163-171.

34. Dias S, Welton NJ, Sutton AJ, Valdwell DM, Guobing L, Ades AE. NICE DSU Technical Support Document 4: Inconsistency in Networks of Evidence Based on Randomised Controlled Trials. 2011. Available from: www.nicedsu.org.uk. Accessed February 1, 2017.

35. Yoshioka H, Mitsudomi T, Morita S, et al. Final overall survival results of WJTOG 3405, a randomized phase 3 trial comparing gefitinib (G) with cisplatin plus docetaxel (CD) as the first-line treatment for patients with non-small cell lung cancer (NSCLC) harboring mutations of the epidermal growth factor receptor (EGFR). J Clin Oncol. 2014;32(5s):abstr8117.

36. Inoue $\mathrm{A}$, Kobayashi $\mathrm{K}$, Maemondo $\mathrm{M}$, et al. Updated overall survival results from a randomized phase III trial comparing gefitinib with carboplatin-paclitaxel for chemo-naive non-small cell lung cancer with sensitive EGFR gene mutations (NEJ002). Ann Oncol. 2013;24(1): 54-59.

37. Zhou $\mathrm{C}, \mathrm{Wu}$ YL, Chen $\mathrm{G}$, et al. Final overall survival results from a randomised, phase III study of erlotinib versus chemotherapy as firstline treatment of EGFR mutation-positive advanced non-small-cell lung cancer (OPTIMAL, CTONG-0802). Ann Oncol. 2015;26(9):1877-1883.

38. Yang J, Wu YL, Schuler M, et al. Afatinib vs cisplatin-based chemotherapy for EGFR mut positive lung adenocarcinoma (LUX-lung 3 and LUX-Lung 6): analysis of OS data from two randomized phase 3 trials. Lancet Oncol. 2015;16(2):141-151.

39. Shi SB, Tang XY, Tian J, Chang CX, Li P, Qi JL. Efficacy of erlotinib plus dendritic cells and cytokine-induced killer cells in maintenance therapy of advanced non-small cell lung cancer. J Immunother. 2014; 37(4):250-255.

40. Sugawara S, Oizumi S, Minato K, et al. Randomized phase II study of concurrent versus sequential alternating gefitinib and chemotherapy in previously untreated non-small cell lung cancer with sensitive EGFR mutations: NEJ005/TCOG0902. Ann Oncol. 2015;26(5):888-894.

41. Hosomi Y, Seto T, Nishio M, et al. Erlotinib plus bevacizumab (EB) versus erlotinib alone (E) as first-line treatment for advanced nonsquamous non-small-cell lung cancer (NSCLC) with activating EGFR mutation (mt): JO25567 exploratory subgroup analysis. Ann Oncol. 2015; 26:ix127-ix147.

42. de Marinis F, Vergnenegre A, Passaro A, et al. Erlotinib-associated rash in patients with EGFR mutation-positive non-small-cell lung cancer treated in the EURTAC trial. Future Oncol. 2015;11(3):421-429.

43. Soo RA, Kawaguchi T, Loh M, et al. Differences in outcome and toxicity between Asian and Caucasian patients with lung cancer treated with systemic therapy. Future Oncol. 2012;8(4):451-462.

44. Herbst RS, Ansari R, Bustin F, et al. Efficacy of bevacizumab plus erlotinib versus erlotinib alone in advanced non-small-cell lung cancer after failure of standard first-line chemotherapy (BeTa): a doubleblind, placebo-controlled, phase 3 trial. Lancet. 2011;377(9780): 1846-1854.

45. Niho S, Kunitoh H, Nokihara H, et al. Randomized phase II study of first-line carboplatin-paclitaxel with or without bevacizumab in Japanese patients with advanced non-squamous non-small-cell lung cancer. Lung Cancer. 2012;76(3):362-367.

46. Telford C, Jones N, Livings C, Batson S. Network meta-analysis comparing overall survival for fulvestrant $500 \mathrm{mg}$ versus alternative therapies for treatment of postmenopausal, estrogen receptor-positive advanced breast cancer following failure on prior endocrine therapy. Clin Breast Cancer. 2016;16(3):188-195. 
47. European Medicines Agency. Assessment Report. Avastin. 2016. Available from: http://www.ema.europa.eu/docs/en_GB/document_ library/EPAR_-_Assessment_Report_-_Variation/human/000582/ WC500210677.pdf. Accessed September 9, 2016.
48. Maemondo M, Fukuhara T, Sugawara S, et al. NEJ026: phase III study comparing bevacizumab plus erlotinib to erlotinib in patients with untreated NSCLC harboring activating EGFR mutations. Ann Oncol. 2016;27(suppl 6):Abstract1286Ti.

\section{Publish your work in this journal}

OncoTargets and Therapy is an international, peer-reviewed, open access journal focusing on the pathological basis of all cancers, potential targets for therapy and treatment protocols employed to improve the management of cancer patients. The journal also focuses on the impact of management programs and new therapeutic agents and protocols on

\section{Dovepress}

patient perspectives such as quality of life, adherence and satisfaction The manuscript management system is completely online and includes a very quick and fair peer-review system, which is all easy to use. Visit http://www.dovepress.com/testimonials.php to read real quotes from published authors. 